\title{
Erratum to: Sex and age effects on cardiovascular autonomic function in healthy adults
}

\author{
Jean-Pierre Ndayisaba ${ }^{1,5} \cdot$ Alessandra Fanciulli $^{1,2} \cdot$ Roberta Granata $^{1}$. \\ Susanne Duerr ${ }^{1} \cdot$ Florian Hintringer $^{3} \cdot$ Georg Goebel $^{4} \cdot$ Florian Krismer $^{1}$. \\ Gregor K. Wenning ${ }^{1,5}$
}

Published online: 13 January 2016

(C) Springer-Verlag Berlin Heidelberg 2016

\section{Erratum to: Clin Auton Res (2015) 25:317-326 DOI 10.1007/s10286-015-0310-1}

The author would like to publish an erratum to correct the two unfortunate errors occurred in the original publication. They are as follows:

1. The total number in the group of subjects ( $>50$ years) is 31 . The complete corrected Table 1 is given in the following page.
2. Under the heading "Active standing versus passive HUT" the word 'the difference' was omitted in the 4th sentence. The complete corrected sentence is given below.

The orthostatic BP fall was greater under HUT than under active standing and the difference was smaller than $5 \mathrm{mmHg}$.

The online version of the original article can be found under doi:10.1007/s10286-015-0310-1.

Jean-Pierre Ndayisaba

jean-pierre.ndayisaba@i-med.ac.at

Gregor K. Wenning

gregor.wenning@i-med.ac.at

1 Department of Neurology, Medical University of Innsbruck, Innsbruck, Austria

2 Department of Neuroscience, Mental Health and Sensory Organs, "Sapienza" University of Rome, Rome, Italy

3 Department of Cardiology, Medical University of Innsbruck, Innsbruck, Austria

4 Department of Medical Statistics, Informatics and Health Economics, Medical University of Innsbruck, Innsbruck, Austria

5 Division of Neurobiology, Department of Neurology, Medical University of Innsbruck, Anichstrasse 35, 6020 Innsbruck, Austria 


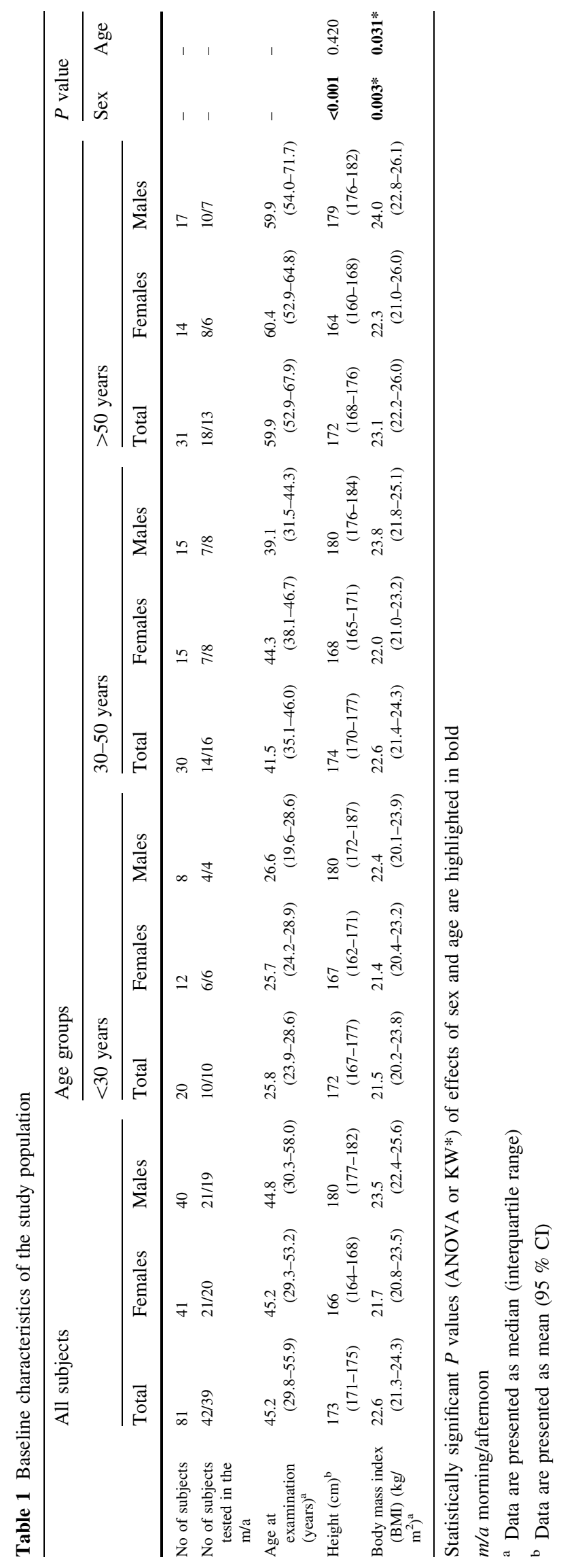

